\title{
Accuracy of intraocular lens power calculation using Scheimpflug tomography and OKULIX ray tracing software in corneal scarring
}

Karim Mahmoud Nabil ( $\nabla$ karim_nabil_ophth@yahoo.com )

University of Alexandria

\section{Research article}

Keywords: Scheimpflug tomography, OKULIX ray tracing software, corneal scarring, third generation IOL power calculation formulas

Posted Date: December 4th, 2019

DOI: https://doi.org/10.21203/rs.2.18091/v1

License: (a) (i) This work is licensed under a Creative Commons Attribution 4.0 International License.

Read Full License 


\section{Abstract}

Background: To evaluate the accuracy of intraocular lens power (IOL) calculation using Scheimpflug tomography and OKULIX ray tracing software in corneal scarring.

Methods: This study was conducted on 40 consecutive eyes, 20 cases with corneal scarring and coexisting cataract, and 20 controls with clear cornea, which underwent uneventful phacoemulsification and IOL implantation following Scheimpflug tomography and OKULIX ray tracing software and third generation IOL power calculation formulas for IOL power calculation. Accuracy of IOL power calculation was evaluated by subtracting expected and achieved spherical refraction 3 months postoperatively and was recorded as mean absolute error (MAE). Distance uncorrected visual acuity (UCVA) for each eye was measured using Snellen chart preoperatively and 3 months postoperatively; visual acuity was scored and converted to the logarithm of the minimum angle of resolution (LogMar).

Results: In cases of corneal scarring, 20 eyes (100\%) yielded a postoperative spherical refraction which differed less than 1 diopter (D) from predicted, in 16 eyes (80\%) the postoperative spherical refraction was within $0.50 \mathrm{D}$ from expected. The MAE was $0.2 \mathrm{D}$ in cases, which did not differ significantly compared to controls (MAE 0.1 D). In corneal scarring cases, distance UCVA showed significant improvement from 1.3 Log Mar (Snellen equivalent 20/400) preoperatively to 0.5 Log Mar (Snellen equivalent 20/60) 3 months postoperatively.

Conclusion: Scheimpflug tomography combined with OKULIX ray tracing software for calculation of IOL power provides accurate results in cases of corneal scarring.

\section{Background}

Patients with corneal scarring pose additional challenges when undergoing cataract surgery. Although in some cases, these patients may benefit from a combined keratoplasty and cataract surgery in the same sitting, sometimes corneal stromal scars have less effect on vision than expected. Undergoing cataract surgery as a first step is sometimes all that is needed to achieve better vision. In these cases, accurate IOL calculation is crucial for visual recovery. ${ }^{[1]}$

Corneal topography and keratometry are the most commonly applied tools to measure the refractive power of the central cornea for IOL power calculation in cataract surgery. Despite both methods provided satisfactory accuracy in measuring

the refractive power of the corneal centre in eyes with regular cornea, such accuracy is limited in cases with scarred cornea and irregular astigmatism. ${ }^{[2-5]}$

The Tomey Topographic Modeling System couples scanning-slit and Placido disk technologies to determine corneal power and curvature. Reconstruction of both posterior and anterior surfaces of the cornea can be achieved from the video-captured slit images, allowing calculation of the total 
anteroposterior corneal power. In scarred corneas, these maps would provide superior accuracy than maps analyzing the anterior surface alone. ${ }^{[6]}$

Lately, a novel IOL power computation software became available relying on numerical ray tracing called OKULIX (Ingenieurbu“ ro der Leu, Hillerse, Germany). ${ }^{[7-10]}$ This software is able to determine the monochromatic optical properties of the pseudophakic eye, assessing optical rays confined to the pupillary zone from cornea to fovea. Unlike conventional lens power calculation formulas, compelling with paraxial rays solely, relying on Gaussian optical principles. The OKULIX computation erratum is similar for all distance points in relation to the optical axis ( $\leq 0.001 \mathrm{D}) .{ }^{[7-12]}$

While numerous reports evaluated the accuracy of calculation of the refractive power of the cornea following laser refractive procedures, studies evaluating the efficiency of intraocular lens power calculation in scarred corneas and irregular astigmatism are lacking. In our study, we evaluated the accuracy of IOL power calculation using Scheimpflug tomography and OKULIX ray tracing software in corneal scarring.

\section{Methods}

Subjects were enrolled from the Ophthalmology department.Informed consent was signed by participants. This research was accepted by the Research Ethics Committee, adhering to the tenets of declaration of Helsinki.

In our prospective study, we enrolled 40 consecutive eyes, 20 cases with corneal scarring and coexisting cataract, and 20 controls with clear cornea, which underwent uneventful phacoemulsification and intraocular lens implantation following Scheimpflug tomography using Topographic Modeling System TMS-5 (Tomey Corporation; Nagoya, Japan) and axial length measurement using the OA-1000 optical biometer (Tomey Corporation; Nagoya, Japan). In the next step, these data were exported to OKULIX ray tracing software for IOL power calculation. IOL power was also calculated using Holladay, SRK II, Hoffer Q and SRK-T formulas with Lenstar LS 900 biometer (Haag-Streit AG, Koeniz, Switzerland). Target refraction was set to zero.

Subjects had phacoemulsification surgery by Alcon Infiniti System (Alcon Laboratories; Ft Worth, TX, USA) and intracapsular implantation of an acrylic posterior chamber IOL. Surgical procedures were undertaken by the same ophthalmic surgeon, the author. The implanted IOLs were the hydrophilic acrylic intraocular lenses (IOLs) Aqua-Sense IOLs (Ophthalmic Innovations International, OII). Cases included were limited to paracentral corneal scarring, not interfering with postoperative refraction. TOPCON RM8900 Auto Refractometer (Topcon Medical Systems; Tokyo, Japan) was applied for postoperative refractive assessment and subjective refraction was undertaken. Snellen chart was used for estimation of uncorrected (UCVA) and best spectacle corrected visual acuity (BCVA), preoperatively and 3 months postoperatively; visual acuity was scored and converted to the logarithm of the minimum angle of resolution (LogMar). 
Accuracy of IOL power calculation was evaluated by subtracting expected and achieved spherical refraction 3 months postoperatively and was recorded as Mean Absolute Error (MAE).

\section{Statistical analysis of the data}

All data were analyzed with the IBM SPSS software package version 20.0. (SPSS Inc., Chicago, IL, USA). Values were recorded as mean $\pm S D$ (standard deviation). Student t-test $(\mathrm{t}$ ) andMann Whitney test $(\mathrm{U})$ were used for parametric comparison of the means. Intra class Correlation (ICC) coefficient and Pearson correlation Coefficient ( $r$ ) were used to assess agreement. A $P$ value less than 0.05 was considered statistically significant.

\section{Results}

Our research involved 40 consecutive eyes, 20 cases with corneal scarring and coexisting cataract, and 20 controls with clear cornea whose data are illustrated in table 1.

The posterior corneal curvature was significantly flatter and the cornea was significantly thinner in cases compared to controls ( $\mathrm{p} 0.038$ and 0.002 respectively) as shown in table 1 .

The cause of corneal scarring in cases was trachomatous trichiasis in 9 cases (45\%), herpes simplex (HS) keratitis in 6 cases (30\%), and trauma in 5 cases (25\%) (Figures 1, 2, 3 \& 4).

The MAE was 0.2 D in cases, which did not differ significantly compared to controls (MAE 0.1 D, p 0.142). In corneal scarring cases, 20 eyes (100\%) showed a postoperative spherical refraction which differed $1.00 \mathrm{D}$ or less from the predicted value, in 16 eyes $(80 \%)$ the postoperative spherical refraction was within $0.50 \mathrm{D}$ from expected. Distance UCVA showed significant improvement in cases with corneal scarring from 1.3 Log Mar (Snellen equivalent 20/400) preoperatively to $0.5 \mathrm{Log}$ Mar (Snellen equivalent 20/60) 3 months postoperatively. Preoperative and 3 months postoperative UCVA was significantly better in controls compared to cases $(p<0.001)$.

Intra class correlation coefficient showed statistically significant agreement between OKULIX ray tracing software and other IOL power calculation formulas in cases and controls $(p<0.001)$ as shown in tables 2 and 3 .

Pearson correlation coefficient revealed statistically significant agreement between OKULIX expected refraction and 3 months subjective refraction in cases and controls $(p<0.001)$ as shown in table 4 .

\section{Discussion}

In the process of IOL power calculation, the corneal power is presented in a single figure: the keratometry $(\mathrm{K})$ value, which is generally computed from the measurement of the central corneal mean anterior radius 
of curvature. Nonetheless, in cases with irregular anterior corneal surface, a solitary figure is not sufficient to accurately present the optics of the cornea and, hence, to precisely calculate the correct IOL power. ${ }^{[13]}$

Since the earliest IOL power calculation formulas by Fyodorov and Gernet to the most modern by Holladay and Olsen, the corneal power was represented only by the Keratometry value, presenting the paraxial power of the cornea, computed by an approximate refractive index of the cornea to assume the non measured posterior corneal surface refractive power. The Keratometry value hypothesizes a spherical corneal shape and speculates a fixed proportion between the anteroposterior corneal curvature. This assumption yields accurate values in normal regular corneas with minimal variations in anteroposterior corneal curvature, which was proven by ray-tracing studies. ${ }^{[14]}$

Nonetheless, scarred corneas with irregular surface exhibit abnormal anteroposterior corneal curvature relation, violating the hypotheses allowing intraocular lens power calculation relying on Keratometry. Furthermore, the accuracy of measurements is frequently hindered in such irregular corneas, usually encountered after corneal refractive procedures, corneal ectasia, scarred corneas, or xerophthalmia. ${ }^{[13]}$

The application of keratometry in the measurement of the refractive power of the cornea relies on two assumptions, the first is that the four measured paracentral points represent the corneal central region, the second is that the corneal centre is comparable to a spherical shape and that the anterior corneal radius is $1.2 \mathrm{~mm}$ flatter than the posterior radius of curvature. ${ }^{[2-4]}$ Although this proves true in regular corneas, it is not applicable in scarred and irregular corneas. ${ }^{[2-5]}$

Computerized videokeratography (CVK) measures $>5000$ points over the corneal surface; therefore providing superior accuracy than manual keratometry in scarred corneas with irregular astigmatism. $[3,15]$ However, topographic corneal power measurement multiplies the anterior corneal curvature by a refractive index, assuming a fixed anteroposterior corneal curvature ratio, to calculate corneal power. ${ }^{[16 \text {, }}$ ${ }^{17]}$ In cases with marked change in the anterior and posterior corneal surfaces relationship, the default refractive index applied by most topography systems is inaccurate. ${ }^{[16,17]}$

The Tomey Topographic Modeling System couples scanning-slit and Placido disk technologies to determine corneal power and curvature. Anteroposterior corneal suface reconstruction can be achieved from the video-captured slit images,

allowing calculation of the total anteroposterior corneal power.

In scarred corneas, these maps would provide superior accuracy than maps analyzing the anterior surface alone. ${ }^{[18]}$

The cornea in cases of herpetic keratitis shows scarring involving the anterior stroma, causing central flattening of the anterior corneal surface with little effect on the posterior curvature. These changes resemble alterations by refractive laser procedures 
and hence, CVK that relies solely on anterior corneal surface analysis would be inaccurate. ${ }^{[18]}$

In Irwin et al study, computerized scanning-slit videokeratography, which analyzes the anterior and posterior surfaces of the cornea, and the contact lens overrefraction

method gave good estimations of corneal power in patients with irregular corneal

astigmatism, improving the accuracy of IOL calculation in patients with corneal pathology and irregular astigmatism. ${ }^{[18]}$

The contact lens overrefraction method is reliable in estimating corneal power in

patients with irregular corneal astigmatism, however, in cases in which the visual acuity is $20 / 70$ or worse, contact lens overrefraction may not be accurate. ${ }^{[18]}$

Lately, OKULIX IOL power computation software became available relying on numerical ray tracing, assessing optical rays confined to the pupillary zone from cornea to fovea, unlike conventional lens power calculation formulas, compelling with paraxial rays solely, relying on Gaussian optical principles. The principles of ray tracing have existed since the $17^{\text {th }}$ century, but only recently have they been applied to calculations for optical devices in ophthalmology. Although many surgeons rely on the use of thirdgeneration IOL power calculation formulas such as the Haigis-L, Hoffer Q, Holladay 2, Olsen, and SRK/T, ray tracing is a modern technique, based on a different set of principles, that should be considered a potentially useful strategy. ${ }^{[19]}$

For a collective of 153 eyes undergoing cataract surgery and applying OKULIX software for IOL power calculation, the mean prediction error was $-0.05 \pm 0.67 \mathrm{D}$. The slope of the regression line $(0.009 \mathrm{D} / \mathrm{mm})$ was not significantly different from zero. ${ }^{[20]}$

In a recent study by M. Ghoreyshi et al., the performance of OKULIX software ray-tracing IOL power calculation was not significantly different compared with

SRK-T and Hoffer Q formulas. The MAE by OKULIX, SRK-T and Hoffer Q formulas, respectively, were 0.42 $( \pm 0.03), 0.36( \pm 0.02)$ and $0.37( \pm 0.02) .{ }^{[21]}$ In the present study, The MAE was $0.2 \mathrm{D}$ in corneal scarring cases, which did not differ significantly compared to controls (MAE 0.1 D, p 0.142). In another study by Karim M Nabil, OKULIX ray-tracing software accuracy was assessed in myopic cataract patients. In $83.33 \%$ of myopic patients, a prediction within $\pm 1.00 \mathrm{D}$ was obtained, whereas $70 \%$ showed a prediction within $\pm 0.5 \mathrm{D}$. The MAE was $0.45 \pm 0.40 \mathrm{D}$. ${ }^{[22]}$ In a third study, OKULIX ray tracing software yielded more accurate minus power intraocular lens calculation in extreme myopia, compared to SRK-T formula. SRK-T calculated IOL power $(-6.3 \pm 2.8 \mathrm{D})$ showed statistically significant difference compared to OKULIX calculated IOL power $(-4.7 \pm 2.6 \mathrm{D})$, rs $0.994 \mathrm{p}<0.001$. ${ }^{[23]}$ 
One of the limitations of our study is the relatively small sample size, which could be justified by the rarity of cases of coexisting cataract and corneal scarring justified to undergo solely phacoemulsification without keratoplasty.

In summary, although corneal topography and keratometry are the most commonly applied tools to measure the refractive power of the central cornea for IOL power calculation in cataract surgery, both methods suffer limitations in cases with corneal scarring and irregular astigmatism.

In these cases, CVK that analyzes the anterior and posterior corneal surfaces

provide a more accurate estimation of corneal power than CVK that analyzes the anterior surface only.

\section{Conclusion}

In conclusion, Scheimpflug tomography combined with OKULIX ray tracing software for calculation of IOL power provides accurate results in cases of corneal scarring.

\section{Abbreviations}

IOL: intraocular lens

MAE: mean absolute error

UCVA: uncorrected visual acuity

LogMar: logarithm of the minimum angle of resolution

D: diopter

SD: standard deviation

ICC: Intra class Correlation coefficient

\section{Declarations}

Ethics approval and consent to participate This study was approved by the Ethics of Research Committee (IRB 00007555, FWA 00015712), Faculty of Medicine, University of Alexandria, Egypt. All procedures performed in studies involving human participants were in accordance with the ethical standards of the institutional and/or national research committee and with the 1964 Declaration of Helsinki and its later amendments or comparable ethical standards. Written informed consent to participate in the study was obtained from all individual participants included in the study.

Consent for publication Written informed consent to publish the results of the study and identifying images or other personal or clinical details of participants that compromise anonymity was obtained 
from all individual participants included in the study.

Availability of data and materials Datasets are available in additional supporting files.

Competing interests The author declares no conflict of interest.

Funding No funding was obtained for this study

Authors' contributions Not applicable

Acknowledgements Not applicable

\section{References}

1. Uday Devgan. Irregular Corneal Astigmatism and Cataract Surgery. Ophthalmology Management, Issue: Cornea Report 2013.

2. Koch DD. Cataract surgery following refractive surgery. Focal Points, Clinical Modules for Ophthalmologists. American Academy of Ophthlamology 2001; 19(5):1-7.

3. Holladay JT. Intraocular lens power calculations for the refractive surgeon. Oper Tech Cataract Refract Surg 1998; 1:105-117.

4. Hamed AM, Wang L, Misra M, Koch DD. A comparative analysis of five methods of determining corneal refractive power in eyes that have undergone myopic laser in situ keratomileusis. Ophthalmology 2002; 109:651-658.

5. Zeh WG, Koch DD. Comparison of contact lens overrefraction and standard keratometry for measuring corneal curvature in eyes with lenticular opacity. J Cataract Refract Surg 1999; 25:898903.

6. Srivannaboon S, Reinstein DZ, Sutton HFS, Holland SP. Accuracy of Orbscan total optical power maps in detecting refractive change after myopic laser in situ keratomileusis. J Cataract Refract Surg 1999; 25:1596-1599.

7. Rabsilber T, Reuland A, Holzer M and Auffarth G. Intraocular lens power calculation using ray tracing following excimer laser surgery. Eye 2007; 21, 697-701.

8. Hoffmann PC, Wahl J, Preußner P-R. Accuracy of intraocular lens calculation with ray tracing. JRefract Surg 2012;28:650-655.

9. Olsen T, Funding M. Ray-tracing analysis of intraocular lens power in situ. J Cataract Refract Surg 2012; 38:641-647.

10. Hoffmann PC, Lindemann CR. Intraocular lens calculation for aspheric intraocular lenses. J Cataract Refract Surg 2013; 39:867-872.

11. Minami K, Kataoka Y, Matsunaga J, Ohtani S, Honbou M, Miyata K. Ray-tracing intraocular lens power calculation using anterior segment optical coherence tomography measurements. J Cataract Refract Surg. 2012;38(10):1758-63. 
12. Saiki M,Negishi K, Kato N,Torii H, Dogru M, Tsubota K. Ray tracing software for intraocular lens power calculation after corneal excimer laser surgery. Jpn J Ophthalmol 2014; 58(3): 276-81.

13. Jaime Aramberri. IOL power calculations in irregular corneas. Cataract and Refractive Surgery Today Europe. March 2017.

14. Canovas C, Abenza S, Alcon E, Villegas E, Marin J, Artal Effect of corneal aberrations on intraocular lens power calculations. J Cataract Refract Surg. 2012;38:1325-1332.

15. Husain S, Kohnen T, Maturi R, Er H, Koch DD. Computerized videokeratography and keratometry in determining intraocular lens calculations. J Cataract Refract Surg 1996; 22:362-366.

16. Seitz B, Langenbucher A, Nguyen NX, Kus MM, Küchle M. Underestimation of intraocular lens power for cataract surgery after myopic photorefractive keratectomy. Ophthalmology 1999; 106:693-702.

17. Ladas JG, Boxer Wachler BS, Hunkeler JD, Durrie DS. Intraocular lens power calculations using corneal topography after photorefractive keratectomy. Am J Ophthalmol 2001; 132:254-255.

18. Irwin Y, Mujtaba A, Steven F, Jay S. Intraocular lens calculations in patients with corneal scarring and irregular astigmatism. J Cataract Refract Surg 2003; 29:1352-1357.

19. Preussner PR. Ray Tracing for IOL Power Calculations. Cataract \& Refractive Surgery Today Europe 2012; 5: 46-48.

20. Preussner PR, Olsen T, Hoffmann P, Findl O. IOL calculation accuracy limits in normal eyes. $J$ Cataract Refract Surg 2008; 34:802-808.

21. Ghoreyshi M, Khalilian A, Peyman M, Mohammadinia M, Peyman A. Comparison of OKULIX raytracing software with SRK-T and Hoffer-Q formula in intraocular lens power calculation. Journal of Current Ophthalmology 2018; 30: 63- 7.

22. Karim MN. Accuracy of intraocular lens power calculation using partial coherence interferometry and OKULIX ray tracing software in high myopic cataract patients. Delta Journal of Ophthalmology 2017, 18:77-80.

23. Karim MN. Accuracy of minus power intraocular lens calculation using OKULIX ray tracing software. Int Ophthalmol 2019, 39:1803-8.

\section{Tables}

Table (1): Comparison between cases and controls according to different parameters 


\begin{tabular}{|c|c|c|c|c|}
\hline & $\begin{array}{c}\text { Cases } \\
(n=20)\end{array}$ & $\begin{array}{c}\text { Controls } \\
(n=20)\end{array}$ & Test of sig. & $\mathrm{p}$ \\
\hline \multicolumn{5}{|l|}{ Age (years) } \\
\hline Mean \pm SD & $58.2 \pm 12$ & $57.9 \pm 17.8$ & \multirow{2}{*}{$t=0.062$} & \multirow[t]{2}{*}{0.951} \\
\hline Median (Min. - Max.) & $61.5(27-73)$ & $65(22-75)$ & & \\
\hline \multicolumn{5}{|l|}{ Cause of corneal scarring } \\
\hline Herpes Simplex keratitis & $6(30 \%)$ & - & \multirow[t]{3}{*}{-} & \multirow[t]{3}{*}{ - } \\
\hline Trauma & $5(25 \%)$ & - & & \\
\hline Trachomatous trichiasis & $9(45 \%)$ & - & & \\
\hline \multicolumn{5}{|l|}{ Keratometric Kf (D) } \\
\hline Mean $\pm \mathrm{SD}$ & $42.9 \pm 2.8$ & $43.2 \pm 1.5$ & \multirow{2}{*}{$t=0.434$} & \multirow[t]{2}{*}{0.667} \\
\hline Median (Min. - Max.) & $43(37.8-42.9)$ & $43.1(40.3-46)$ & & \\
\hline \multicolumn{5}{|l|}{ Keratometric Ks (D) } \\
\hline Mean \pm SD & $45 \pm 3.9$ & $44.3 \pm 1.6$ & \multirow[t]{2}{*}{$t=0.709$} & \multirow[t]{2}{*}{0.484} \\
\hline Median (Min. - Max.) & $44.1(38.7-55.9)$ & $44.5(42-48)$ & & \\
\hline \multicolumn{5}{|l|}{ Keratometric Avg K (D) } \\
\hline Mean \pm SD & $43.9 \pm 3.1$ & $43.8 \pm 1.5$ & \multirow[t]{2}{*}{$\mathrm{t}=0.229$} & \multirow[t]{2}{*}{0.820} \\
\hline Median (Min. - Max.) & 43.7(38.3 - 53.9) & $43.9(41.3-46.5)$ & & \\
\hline \multicolumn{5}{|l|}{ Posterior Kf (mm) } \\
\hline Mean \pm SD & $-6.1 \pm 0.6$ & $-5.9 \pm 0.3$ & \multirow[t]{2}{*}{$t=1.138$} & \multirow[t]{2}{*}{0.266} \\
\hline Median (Min. - Max.) & $-6(-7.4--4.8)$ & $-6(-6.3--5.4)$ & & \\
\hline \multicolumn{5}{|l|}{ Posterior Ks (mm) } \\
\hline Mean $\pm \mathrm{SD}$ & $-6.8 \pm 0.8$ & $-6.2 \pm 0.3$ & \multirow[t]{2}{*}{$\mathrm{t}=2.885^{*}$} & \multirow[t]{2}{*}{$0.008^{*}$} \\
\hline Median (Min. - Max.) & $-6.6(-8.2--5.1)$ & $-6.2(-6.8--5.7)$ & & \\
\hline \multicolumn{5}{|l|}{ Posterior Avg K (mm) } \\
\hline Mean $\pm \mathrm{SD}$ & $-6.4 \pm 0.7$ & $-6.1 \pm 0.2$ & \multirow[t]{2}{*}{$\mathrm{t}=2.202^{*}$} & \multirow[t]{2}{*}{$0.038^{*}$} \\
\hline Median (Min. - Max.) & $-6.3(-7.8--5)$ & $-6.1(-6.6--5.6)$ & & \\
\hline \multicolumn{5}{|l|}{ Pachymetry apex ( $\mu)$} \\
\hline Mean $\pm \mathrm{SD}$ & $513.8 \pm 36.3$ & $546 \pm 23.8$ & \multirow[t]{2}{*}{$t=3.321^{*}$} & \multirow[t]{2}{*}{$0.002^{*}$} \\
\hline Median (Min. - Max.) & $512.5(451-594)$ & $551.5(506-579)$ & & \\
\hline \multicolumn{5}{|c|}{ Pachymetry thinnest location $(\mu)$} \\
\hline Mean \pm SD & $473.8 \pm 61.1$ & $539.4 \pm 23.1$ & $\mathrm{t}=4.496^{*}$ & $<0.001^{*}$ \\
\hline Median (Min. - Max.) & $478(290-582)$ & 544(502-572) & & \\
\hline Axial length (mm) & & & & \\
\hline Mean \pm SD & $25.3 \pm 3.8$ & $24.8 \pm 3$ & $\mathrm{U}=174.50$ & 0.495 \\
\hline Median (Min. - Max.) & $23.9(21.9-34.3)$ & $23.5(22-31.4)$ & & \\
\hline OKULIX calculated IOL pov & & & & \\
\hline Mean \pm SD & $16.2 \pm 9.5$ & $16.8 \pm 8$ & $\mathrm{U}=194.00$ & 0.883 \\
\hline Median (Min. - Max.) & $20.8(-2-26)$ & 20.8(2- 25) & & \\
\hline
\end{tabular}




\begin{tabular}{|c|c|c|c|c|}
\hline & $\begin{array}{l}\text { Cases } \\
(n=20)\end{array}$ & $\begin{array}{l}\text { Control } \\
(\mathrm{n}=20)\end{array}$ & $\bar{U}$ & $\mathrm{p}$ \\
\hline \multicolumn{5}{|c|}{ OKULIX expected Refraction (D) } \\
\hline Mean \pm SD & $0 \pm 0.4$ & $-0.1 \pm 0.2$ & 196.0 & 0.925 \\
\hline Median (Min. - Max.) & $-0.1(-0.7-0.6)$ & $0(-0.4-0.2)$ & & \\
\hline \multicolumn{5}{|c|}{3 months subjective refraction (D) } \\
\hline Mean \pm SD & $0.1 \pm 0.5$ & $-0.1 \pm 0.2$ & 180.0 & 0.602 \\
\hline Median (Min. - Max.) & $0(-0.8-1)$ & $0(-0.3-0.3)$ & & \\
\hline \multicolumn{5}{|l|}{ MAE (D) } \\
\hline Mean \pm SD & $0.2 \pm 0.2$ & $0.1 \pm 0.1$ & 145.50 & 0.142 \\
\hline Median (Min. - Max.) & $0.2(0-0.6)$ & $0.1(0-0.2)$ & & \\
\hline \multicolumn{5}{|c|}{ Pre-operative UCVA Log Mar } \\
\hline Mean \pm SD & $1.5 \pm 0.5$ & $0.8 \pm 0.3$ & $58.0^{*}$ & $<0.001^{*}$ \\
\hline Median (Min. - Max.) & $1.3(0.7-2)$ & $0.7(0.5-1.3)$ & & \\
\hline \multicolumn{5}{|c|}{$\begin{array}{l}3 \text { months post-operative UCVA Log } \\
\text { Mar }\end{array}$} \\
\hline Mean \pm SD & $0.6 \pm 0.3$ & $0.2 \pm 0.1$ & $18.0^{*}$ & $<0.001^{*}$ \\
\hline Median (Min. - Max.) & $0.5(0.2-1.3)$ & $0.2(0-0.3)$ & & \\
\hline \multicolumn{5}{|c|}{$\begin{array}{l}3 \text { months post-operative BCVA Log } \\
\text { Mar }\end{array}$} \\
\hline Mean \pm SD & $0.5 \pm 0.2$ & $0.1 \pm 0.1$ & $12.0^{*}$ & $<0.001^{*}$ \\
\hline Median (Min. - Max.) & $0.5(0.2-0.8)$ & $0(0-0.2)$ & & \\
\hline \multicolumn{5}{|c|}{ SRK-T calculated IOL power (D) } \\
\hline Mean $\pm \mathrm{SD}$ & $16 \pm 9.2$ & $16.6 \pm 7.6$ & 191.0 & 0.820 \\
\hline Median (Min. - Max.) & $\begin{array}{l}20.4(-3.8- \\
24.5)\end{array}$ & $\begin{array}{l}20.5(2.2- \\
24.4)\end{array}$ & & \\
\hline \multicolumn{5}{|c|}{ Hoffer Q calculated IOL power (D) } \\
\hline Mean \pm SD & $15.9 \pm 9.4$ & $16.4 \pm 8$ & 190.50 & 0.799 \\
\hline Median (Min. - Max.) & $\begin{array}{l}20.4(-4.8- \\
24.8)\end{array}$ & $\begin{array}{l}20.5(1.4- \\
25.2)\end{array}$ & & \\
\hline \multicolumn{5}{|c|}{ SRK II calculated IOL power (D) } \\
\hline Mean $\pm \mathrm{SD}$ & $16 \pm 9.1$ & $16.6 \pm 7.3$ & 194.0 & 0.883 \\
\hline Median (Min. - Max.) & $\begin{array}{l}20.3(-5.6- \\
24.5)\end{array}$ & $\begin{array}{l}20.5(1.5- \\
23.8)\end{array}$ & & \\
\hline \multicolumn{5}{|c|}{ Holladay calculated IOL power (D) } \\
\hline Mean \pm SD & $16 \pm 9.3$ & $16.5 \pm 7.9$ & 190.50 & 0.799 \\
\hline Median (Min. - Max.) & $20.5(-4-24.6)$ & $\begin{array}{l}20.6(1.7- \\
24.9)\end{array}$ & & \\
\hline
\end{tabular}

t: Student t-test

U: Mann Whitney test

$\mathrm{p}$ : $\mathrm{p}$ value for comparing between the two studied groups

*: Statistically significant at $\mathrm{p} \leq 0.05$ 
$\mathrm{Kf}=$ flattest corneal meridian, $\mathrm{Ks}=$ steepest corneal meridian, $\mathrm{D}=$ diopters, $\mathrm{Avg}=$ average $, \mu=\mathrm{microns}, \mathrm{mm}=$ millimetre, UCVA = uncorrected visual acuity, BCVA = Best spectacle corrected visual acuity, Log Mar = logarithm of minimal angle of resolution, $\mathrm{mm}=$ millimeters, $\mathrm{IOL}=$ intraocular lens, $\mathrm{MAE}=$ mean absolute error, $\mathrm{SRK}=$ Sanders, Retzlaff, Kraff

Table (2): Intra class correlation coefficient for OKULIX versus other IOL power calculation formulas in cases

\begin{tabular}{lccc}
\hline & ICC coefficient & $95 \%$ C.I & p \\
\hline $\begin{array}{l}\text { OKULIX IOL power vs. } \\
\text { SRK-T }\end{array}$ & 0.995 & $0.987-0.998<0.001^{*}$ \\
\hline Hoffer Q & 0.995 & $0.986-0.998<0.001^{*}$ \\
\hline SRK II & 0.987 & $0.969-0.995<0.001^{*}$ \\
Holladay & 0.995 & $0.988-0.998<0.001^{*}$
\end{tabular}

SRK-T vs.

\begin{tabular}{lll}
\hline Hoffer Q & 0.999 & $0.997-1.000<0.001^{*}$ \\
\hline SRK II & 0.997 & $0.994-0.999<0.001^{*}$ \\
\hline Holladay & 0.999 & $0.999-1.000<0.001^{*}$
\end{tabular}

Hoffer Q vs.

\begin{tabular}{lll} 
SRK II & 0.996 & $0.990-0.998<0.001^{*}$ \\
\hline Holladay & 1.000 & $0.999-1.000<0.001^{*}$
\end{tabular}

SRK II vs.

Holladay

0.996

$0.990-0.998<0.001^{*}$

ICC: Intra class Correlation coefficient

*: Statistically significant at $\mathrm{p} \leq 0.05$

Table (3): Intra class correlation coefficient for OKULIX versus other IOL power calculation formulas in controls 


\begin{tabular}{llll}
\hline ICC coefficient & $95 \%$ C.I & p \\
\hline
\end{tabular}

OKULIX IOL power vs.

\begin{tabular}{lll} 
SRK-T & 0.986 & $0.964-0.994<0.001^{*}$ \\
\hline Hoffer Q & 0.985 & $0.964-0.994<0.001^{*}$ \\
\hline SRK II & 0.980 & $0.950-0.992<0.001^{*}$ \\
\hline Holladay & 0.987 & $0.968-0.995<0.001^{*}$
\end{tabular}

\section{SRK-T vs.}

\begin{tabular}{lll}
\hline Hoffer Q & 0.998 & $0.995-0.999<0.001^{*}$ \\
\hline SRK II & 0.997 & $0.991-0.999<0.001^{*}$ \\
\hline Holladay & 0.999 & $0.998-1.000<0.001^{*}$
\end{tabular}

Hoffer Q vs.

\begin{tabular}{lll} 
SRK II & 0.991 & $0.979-0.997<0.001^{*}$ \\
\hline Holladay & 1.000 & $0.999-1.000<0.001^{*}$
\end{tabular}

SRK II vs.

Holladay $\quad 0.993 \quad 0.984-0.997<0.001^{*}$

ICC: Intra class Correlation coefficient

*: Statistically significant at $\mathrm{p} \leq 0.05$

Table (4): Agreement between OKULIX expected refraction and 3 months subjective refraction in cases and controls

\begin{tabular}{ccccc}
\hline $\begin{array}{c}\text { OKULIX expected refraction } \\
\text { versus 3 months subjective } \\
\text { refraction }\end{array}$ & $\begin{array}{c}\text { Mean } \\
\text { difference } \\
\text { (SD) }\end{array}$ & $\begin{array}{c}\text { 95\% limits of } \\
\text { agreement }\end{array}$ & $\begin{array}{c}\text { Pearson } \\
\text { correlation } \\
\text { Coefficient (r) }\end{array}$ & p-value \\
\hline Cases & $-0.11(0.30)$ & 0.49 to -0.70 & 0.804 & $<0.001^{*}$ \\
Control & $0.01(0.12)$ & 0.25 to -0.23 & 0.809 & $<0.001^{*}$ \\
\hline
\end{tabular}

r: Pearson coefficient

*: Statistically significant at $\mathrm{p} \leq 0.05$

\section{Figures}



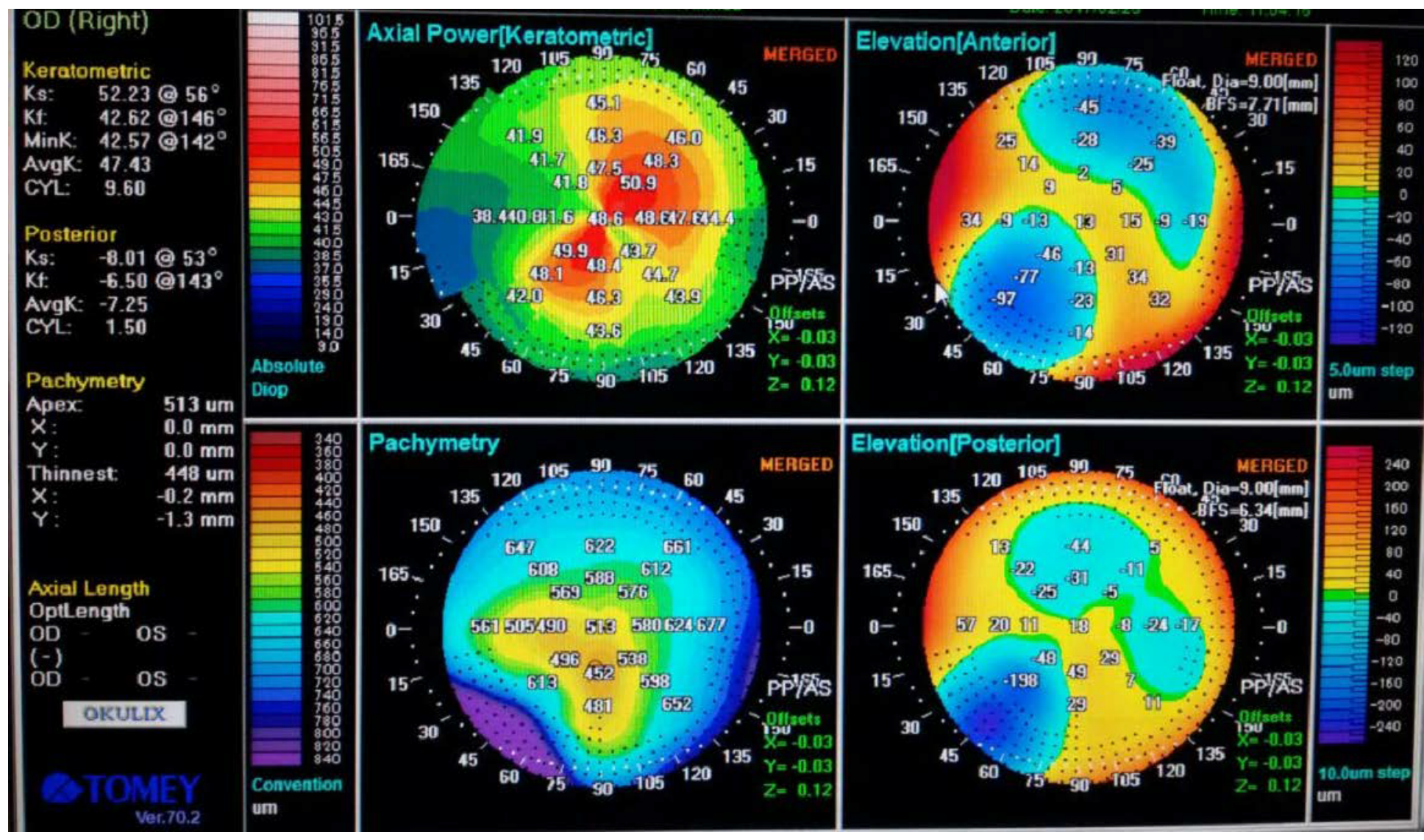

Figure 1

Scheimpflug tomography of a patient with corneal scarring secondary to herpes simplex keratitis.

(Original figure)

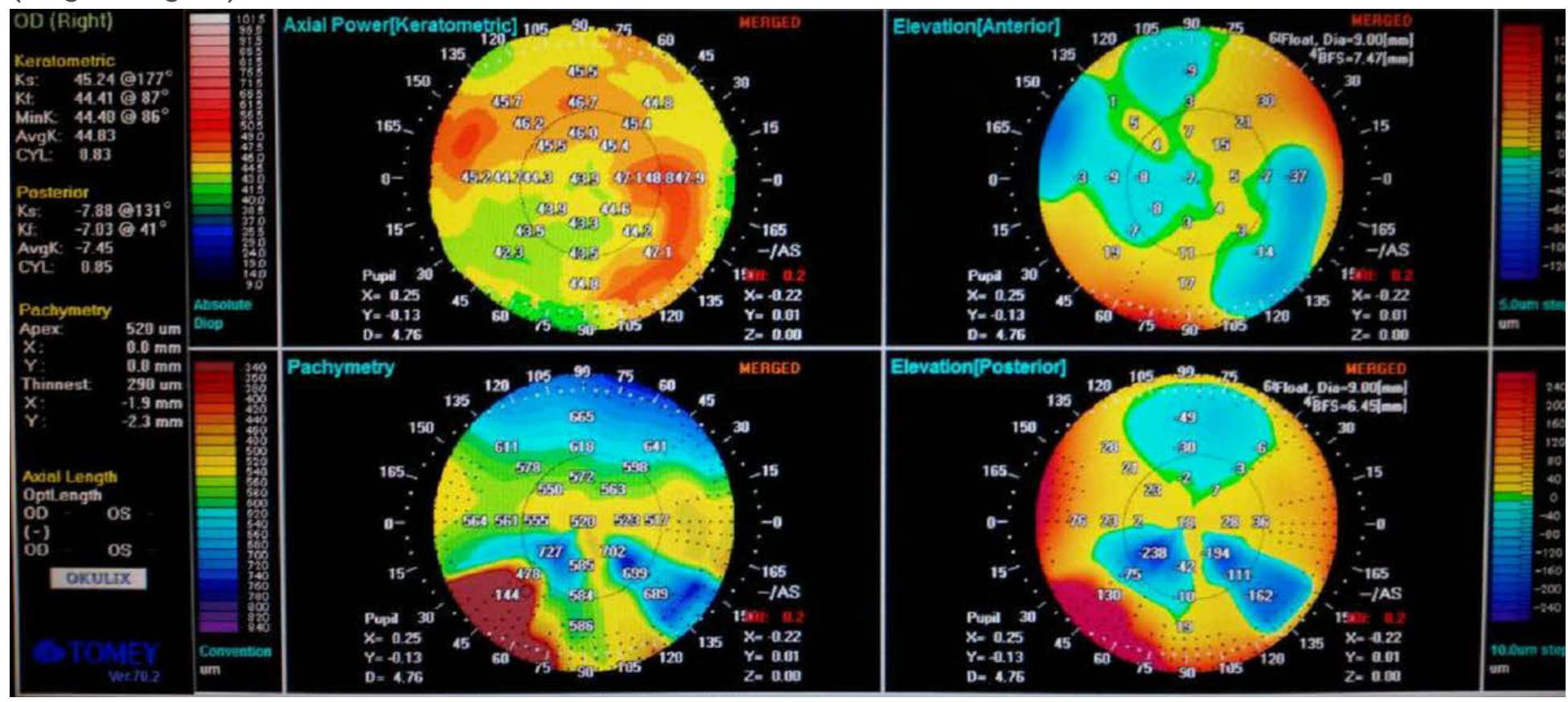

Figure 2 
Scheimpflug tomography of a patient with corneal scarring secondary to trachomatous trichiasis. (Original figure)

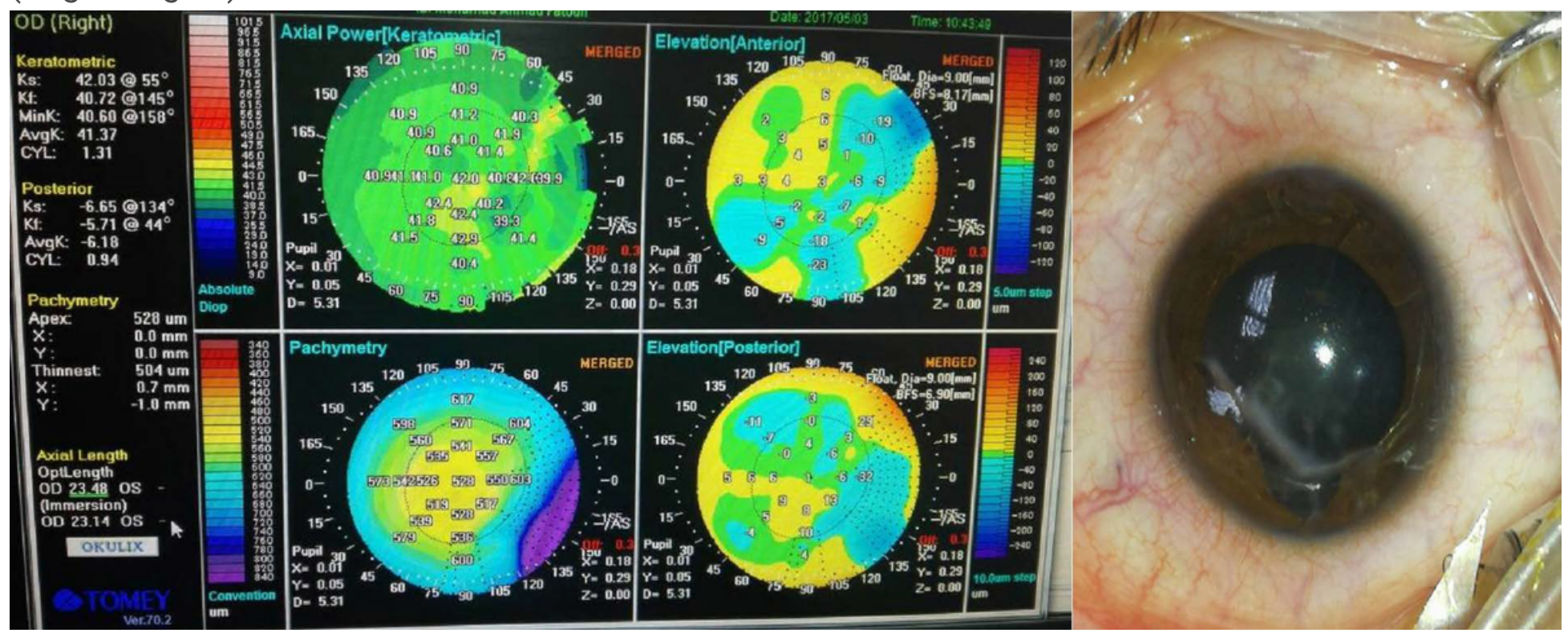

\section{Figure 3}

Left: Scheimpflug tomography of a patient with corneal scarring secondary to trauma. Right: Preoperative picture showing paracentral traumatic corneal scarring. (Original figure) 


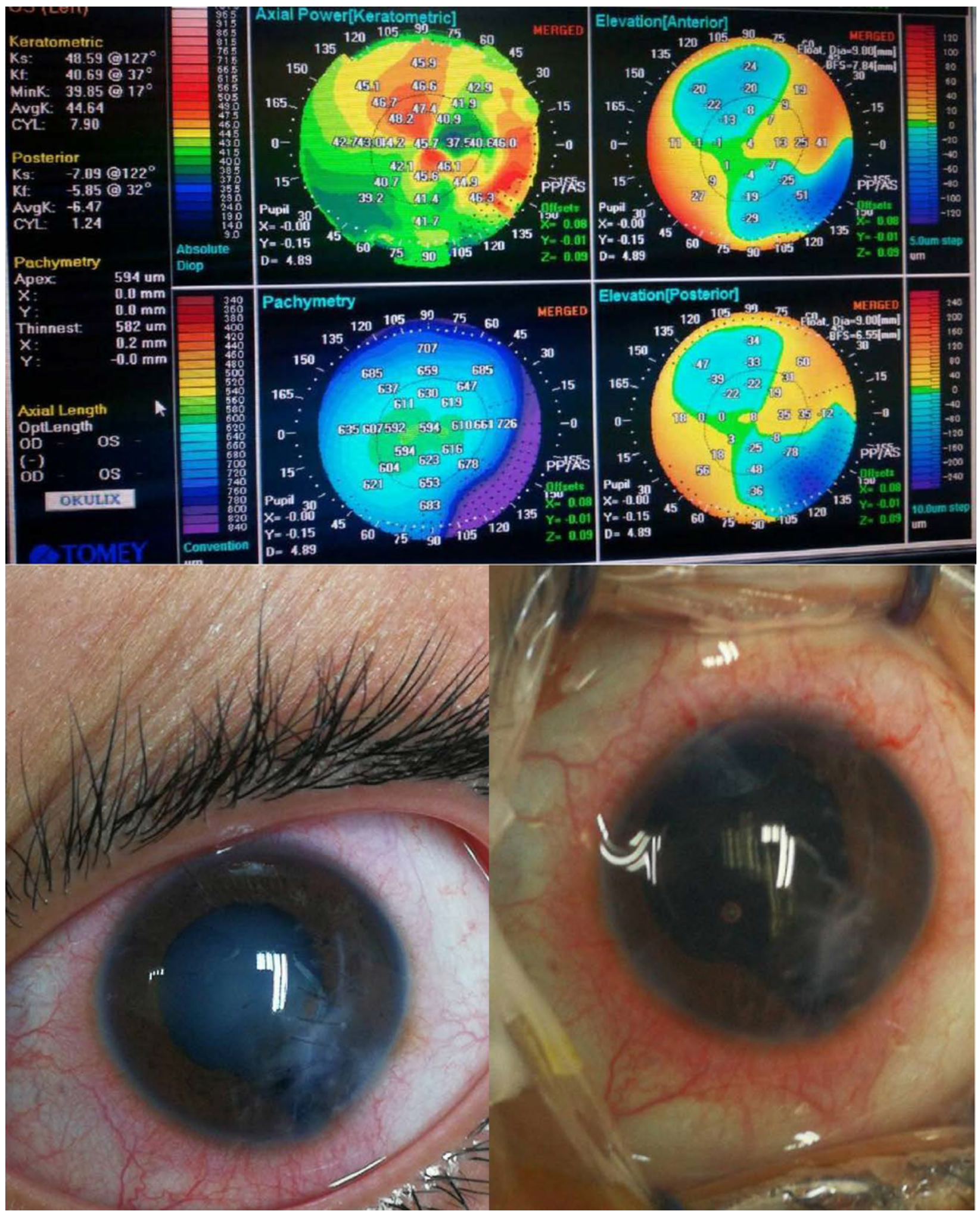

Figure 4

Top: Scheimpflug tomography of a patient with corneal scarring secondary to trauma. Bottom left: Preoperative picture showing paracentral traumatic corneal scarring. Bottom right: Postoperative picture. (Original figure)

\section{Supplementary Files}


This is a list of supplementary files associated with this preprint. Click to download.

- Book1.xlsx 